\title{
Novel Microbial Sources of Tropane Alkaloids: First Report of Production by Endophytic Fungi Isolated from Datura metel $\mathbf{L}$.
}

\author{
Tanushree Naik $^{1}$ Shanadrahalli Chandrashekaraiah Vanitha ${ }^{1} \cdot$ \\ Pradumn Kumar Rajvanshi ${ }^{1}$ - Manjegowda Chandrika ${ }^{1}$ - Subban Kamalraj ${ }^{1}$. \\ Chelliah Jayabaskaran ${ }^{1}$
}

Received: 24 April 2017 / Accepted: 7 October 2017 / Published online: 24 October 2017

(C) Springer Science+Business Media, LLC 2017

\begin{abstract}
Eighteen endophytic fungi were isolated from various tissues of Datura metel and genes encoding for putrescine $N$-methyltransferase (PMT), tropinone reductase 1 (TR1) and hyoscyamine $6 \beta$-hydroxylase (H6H) were used as molecular markers for PCR-based screening approach for tropane alkaloids (TAs) producing endophytic fungi. These fungi were identified taxonomically by sequence analysis of the internal transcribed spacer region (ITS1-5.8S-ITS2) and also based on morphological characteristics of the fungal spore as Colletotrichum boninense, Phomopsis sp., Fusarium solani, Colletotrichum incarnatum, Colletotrichum siamense and Colletotrichum gloeosporioides. The production of TAs hyoscyamine and scopolamine by the fungi has been
\end{abstract}

Tanushree Naik and Shanadrahalli Chandrashekaraiah Vanitha have contributed equally to this study.

Electronic supplementary material The online version of this article (doi:10.1007/s00284-017-1367-y) contains supplementary material, which is available to authorized users.

Chelliah Jayabaskaran

cjb@biochem.iisc.ernet.in

Tanushree Naik

tanushree.naik@gmail.com

Shanadrahalli Chandrashekaraiah Vanitha

vanitha_cshekhar@yahoo.co.in

Pradumn Kumar Rajvanshi

pradumn.rajvanshi@gmail.com

Manjegowda Chandrika

chandrika.manjegowda82@gmail.com

Subban Kamalraj

mycolkamal@gmail.com

1 Department of Biochemistry, Indian Institute of Science, Bangalore 560 012, India ascertained using chromatography and spectroscopy methods by comparison with the standards. Among the fungi, the highest yields of hyoscyamine $(3.9 \mathrm{mg} / \mathrm{L})$ and scopolamine $(4.1 \mathrm{mg} / \mathrm{L})$ were found in $C$. incarnatum culture. This is the first report of endophytic fungi possess the PMT, TRl and $\mathrm{H} 6 \mathrm{H}$ genes and produces TAs. These endophytic fungi have significant potential to be applied in fermentation technology to meet the demands for TAs economically.

\section{Introduction}

Tropane alkaloids (TAs), scopolamine and its precursor hyoscyamine, are produced by some genera of Solanaceae family namely Atropa, Datura, Duboisia, Hyoscyamus and Scopolia [7]. They are extensively used as anticholinergic agents [30], anaesthetics and in the treatment of motion sickness [15]. Scopolamine remains to be the preferred drug because of its lesser side effects than hyoscyamine. Scopolamine plays an important role in plant defence mechanism due to its implication in hampering the growth of insect larvae [27]. The roots are reported to be the site of scopolamine production from where it is translocated to other parts of the plant [19]. Large quantities of plant material are required for the production of these drugs as their alkaloid contents is low. Therefore, extensive efforts have been made in the recent years to facilitate the production of these valuable TAs from callus and hairy root cultures of TA-producing solanaceae plants by adapting different biotechnological approaches. But, they only accumulate in hairy root and are completely absent in callus and all suspension cultures [17]. Overexpression of $P M T$ and $H 6 H$ genes in transgenic hairy root culture of Hyoscyamus niger and Atropa baetica has been used for the production of TAs 
$[29,30]$. Several approaches attempted in plant cell and organ culture systems failed to increase the accumulation of these alkaloids. The yields obtained so far are too low to allow commercial production. Efforts are on to look for alternate sources of these alkaloids.

Plant and endophytic fungi through mutualistic symbiosis produce secondary metabolites [8]. Ancient horizontal gene transfer is thought to have occurred between plants and microbes [20]. There is also a considerable amount of evidence showing that endophytes produce bioactive secondary metabolites associated with the host plant [5]. Datura metel L. (local name 'thorn apple'), is one of the medicinal plant and it is a rich source of the TAs hyoscyamine and scopolamine [22]. D. metel had been studied earlier for the composition, diversity and distribution of endophytic fungi within the plant $[1,21]$. Some bioactive products have also been reported from endophytic fungi of $D$. metel from our lab [10], but not hyoscyamine and scopolamine or their structural analogues. We report here for the first time that the production of hyoscyamine and scopolamine by endophytic fungi isolated from $D$. metel plant and identified them based on molecular and morphological studies. The TAs production was confirmed by chromatographic and spectroscopic methods.

\section{Materials and Methods}

\section{Plant Material and Isolation of Endophytic Fungi}

Samples of $D$. metel fresh and healthy roots, stems and leaves were collected from the nursery, Indian Institute of Science, Bangalore, India. The plant parts were thoroughly washed with running tap water, rinsing with sterile distilled water (SDW) and then treated with $20 \%$ commercial bleach with $0.1 \%$ Tween-20 for 5 min and later again rinsed in SDW. They were then soaked in $100 \mathrm{~mL}$ solution containing fungicide bavistin $(30 \mathrm{mg})$, tetracycline $(0.6 \mathrm{mg})$, rifampicin $(0.6 \mathrm{mg})$ and $0.1 \%$ Tween-20 for $20 \mathrm{~min}$ and rinsed in SDW. All samples were finally surface sterilized with $0.1 \%$ mercuric chloride for $10 \mathrm{~min}$, followed by five to six washings with SDW. The surface sterilized root and stem segments were cut in to small pieces (1-2 $\mathrm{mm})$, leaves were cut into $1 \mathrm{~cm}^{2}$ pieces and placed on petri plates containing potato dextrose agar (PDA) supplemented with $100 \mathrm{mg} / \mathrm{L}$ ampicillin. The plates were labelled and incubated at $25 \pm 2{ }^{\circ} \mathrm{C}$ with $12 \mathrm{~h}$ photoperiod or in darkness. The fungal mycelia that emerged from the cut surface of the segments after several days were transferred on to fresh PDA plates [18].
DNA Extraction and Genomic PCR-Based Screening for TAs-Producing Fungi

Eighteen different endophytic fungi were isolated and cultured in PDB medium. The genomic DNA was extracted from their mycelium and also from $D$. metel leaves by CTAB method [9]. The DNA quality was visualized under UV light, quantified by nanodrop and used for polymerase chain reaction (PCR) analysis. All endophytic fungi were screened for the presence of $N$-methyltransferase $(P M T)$, tropinone reductase $1(T R I)$ and hyoscyamine $6 \beta$-hydroxylase $(H 6 H)$ genes as molecular markers for TAs-producing fungi and $D$. metel gDNA was used as positive control. Based on the conserved sequences of PMT, TRI and $H 6 H$, the gene specific primers were designed and synthesized (Table S1). Each PCR reaction was performed in atotal volume of $25 \mu \mathrm{L}$ reaction mixture containing $10 \mu \mathrm{M}$ of each forward and reverse primer, $200 \mu \mathrm{M}$ of each of the four dNTPs, 1 Unit Taq DNA polymerase and $100 \mathrm{ng}$ template DNA. The PCR programme detail is given in Table S1. The amplified DNA fragments were analysed by agarose gel electrophoresis, purified using a GeneJET ${ }^{\mathrm{TM}} \mathrm{Gel}$ Extraction kit, (Thermo Scientific, Waltham, MA, USA), sequenced and analysed with BLAST in the NCBI database.

\section{Identification of Endophytic Fungi}

The DNA of six PCR positive fungal isolates was used for the PCR amplification of ITS regions to identify the fungal isolates. The universal primers ITS1 and ITS4 (Table S1) were used for the amplification of the rDNA region of ITS1 and ITS2 and the 5.8SrRNA gene. The PCR reaction mixture contained all of the components as the same concentration described above and PCR programme details is given in Table S1. The PCR products were purified, sequenced and analysed as mentioned above. Sequence data were aligned and compared with sequences deposited in the GenBank data base NCBI BLASTIN programme. The fungi were assigned to a genus based in a $99-100 \%$ similarity index.

Mycelia pattern and conidial morphology of the six fungi were also determined using a light microscopy (Zeiss AX10 Imager A2, Zeiss, Germany). At least 30-50 conidia were studied for each isolate separately and their all characters determined and compared to that of the already reported $[13,16,25]$ species.

\section{Extraction of TAs from Endophytic Fungi}

Six endophytic fungi were grown in $500 \mathrm{~mL}$ Erlenmeyer flask containing $100 \mathrm{~mL}$ modified nutrient growth medium (MNGB: Peptone $5 \mathrm{~g} / \mathrm{L}$, Yeast extract $3 \mathrm{~g} / \mathrm{L}$, Malt extract $3 \mathrm{~g} / \mathrm{L}$, Dextrose $10 \mathrm{~g} / \mathrm{L}, \mathrm{pH} 7.0 \pm 0.2$ ) and incubated at $28 \pm 2{ }^{\circ} \mathrm{C}$ for 21 days. After 3 weeks of still culture, the 
mycelia were harvested by filtration. Mycelia were thoroughly washed with sterile water, weighed and ground to fine powder using a mortar and pestle. The powdered mycelia and culture filtrate were processed independently for TAs extraction according to Gontier and Sangwan [6]. The culture filtrate and powdered mycelial material were extracted with the equal volume of methanol:chloroform:ammonia solution $(50: 50: 1.4, \mathrm{v} / \mathrm{v} / \mathrm{v})$. The lower organic phase was collected and the solvent was then removed by rotary evaporator under reduced pressure at $40{ }^{\circ} \mathrm{C}$. The residues were dissolved in $40 \mathrm{~mL}$ of $0.1 \mathrm{~N} \mathrm{HCl}$. After addition of $3 \mathrm{~mL}$ of ammonia solution, the alkaloids were extracted with $3 \times 30 \mathrm{~mL}$ chloroform. After that the chloroform extracts were evaporated to dryness under reduced pressure at $40{ }^{\circ} \mathrm{C}$. The dry residue was dissolved in $1 \mathrm{~mL}$ methanol for further use.

\section{Detection of TAs from Fungal Extracts by Thin Layer Chromatography (TLC)}

Extracted samples and standards hyoscyamine and scopolamine were separated by TLC on silica gel 60 GF259 (Merck, Kenilworth, USA) using a solvent system consisting of chl oroform:methanol:acetone:ammonia (75:15:10:2, v/v/v/v). The alkaloids were detected by spraying the alkaloid specific Dragendorff's reagent on the plate. The spots showing $R_{f}$ values corresponding to standard hyoscyamine and scopolamine (Sigma Aldrich, India) were scraped off from the nonsprayed TLC plate and eluted with methanol and purified fungal TAs were used for further analysis.

\section{Quantification of TAs by High Performance Liquid Chromatography (HPLC)}

The quantitative estimation of alkaloids from six fungal extracts was performed by HPLC. An Agilent 1120 HPLC system was used for separation. A photo iodide array detector measuring absorbance at $217 \mathrm{~nm}$. A Phenomenex Luna C18 $(5 \mu \mathrm{m}, 250 \times 4.6 \mathrm{~mm})$ column was employed and fungal extracts were separated by using an isocratic elution of mobile phase consisting of $83 \%$ phosphate buffer saline $(\mathrm{pH}$ 3.3): $17 \%$ acetonitrile. The flow rate of mobile phase was set at $1.0 \mathrm{~mL} \mathrm{~min}{ }^{-1}$ using standards. The concentrations of hyoscyamine and scopolamine in the extracts were calculated by comparison with peak intensity obtained from standards.

\section{Electrospray Ionization Mass Spectrometry/Mass Spectrometry (ESI-MS/MS) Analysis}

The purified fungal samples were subjected to mass spectrometry (Thermo Electron Corporation, CA, USA) analysis. The conditions for MS/MS were as follows: the determination mode was in scan mode, the ion-dipole was positive ion, the ionization mode was electro spray ionization (ESI), the nebulizer gas (helium) at a flow rate of $1 \mathrm{~mL} \mathrm{~min}{ }^{-1}$, the capillary temperature was $275{ }^{\circ} \mathrm{C}$ and the capillary voltage was $16 \mathrm{~V}$. the data acquired over an range of 50-350 in positive ion mode and analysed using the xcalibur analysis software.

\section{Results}

\section{Screening and Identification of Endophytic Fungi for Producing TAs}

A total of 18 endophytic fungi were isolated from plant tissues, viz, leaf, root, stem and their fungal genome screened for the presence of TA biosynthetic genes. Out of 18 fungi, 6 fungi were found to be PCR positive for the conserved sequences of the PMT (196 and $256 \mathrm{bp})$, TRI (208 bp) and $H 6 H$ (378 bp) genes (Fig. 1a-d). The sequence analysis of the PMT, TRl and H6H showed 99, 93 and 100\% homology, respectively, with the host plant gene sequence (Table S2). The sequences of PMT, TRI and H6H DNA fragments have been deposited at the NCBI GenBank database with the accession numbers KM897684, KT358856, KT358857, KR024334, KT366043, KT366042, KT358853, KT358854, KT358855, KT358850, KT358851, KT358852 and KT358844, KT358845, KT358846, KT358847, KT358848, KT358849, respectively. These results confirmed the presence of PMT, TRI and $H 6 H$ genes involved in TAs biosynthesis pathway in the six fungal isolates thus indicating their potential for production of hyoscyamine and scopolamine.

The six fungi amplified the $600 \mathrm{bp}$ amplicon of ITS region and their sequences were blast analysed, which showed maximum homology with the earlier NCBI database. This molecular information was supporting with the morphological data, based on both results the endophytic fungi were identified as Colletotrichum boninense (Dm 9.3), Phomopsis sp. (Dm 10.2), Fusarium solani (Dm 13.4), Colletotrichum incarnatum (Dm 16.3), Colletotrichum siamense (Dm 17.3) and Colletotrichum gloeosporioides (Dm 18.2). The ITS sequences of six fungi were deposited to NCBI Genbank with the accession numbers (Fig S2). The detailed information for the identification is given in Supplementary results, Table S3, Figs. S1 and S2.

\section{Structural Elucidation and Quantitation of Hyoscyamine and Scopolamine}

The fungal extracts were assessed for the presence of hyoscyamine and scopolamine. The TLC analysis of fungal extracts showed the brown spots corresponding to standard hyoscyamine and scopolamine with the $R_{f}$ value 0.21 and 
Fig. 1 Representative genomic PCR analysis for the presence of genes encoding PMT (a, b), TRI (c) and $H 6 H(\mathbf{d})$ in endophytic fungi. Lane 1: DNA markers (100 bp ladder), Lane 2: positive control (PCR product of gDNA of D. metel), Lanes 3-8 PCR products of Dm 9.3, Dm 10.2, Dm 13.4, Dm 16.3, Dm 17.3 and Dm 18.2, respectively, Lane 9: negative control (-template). Arrows show the amplified products
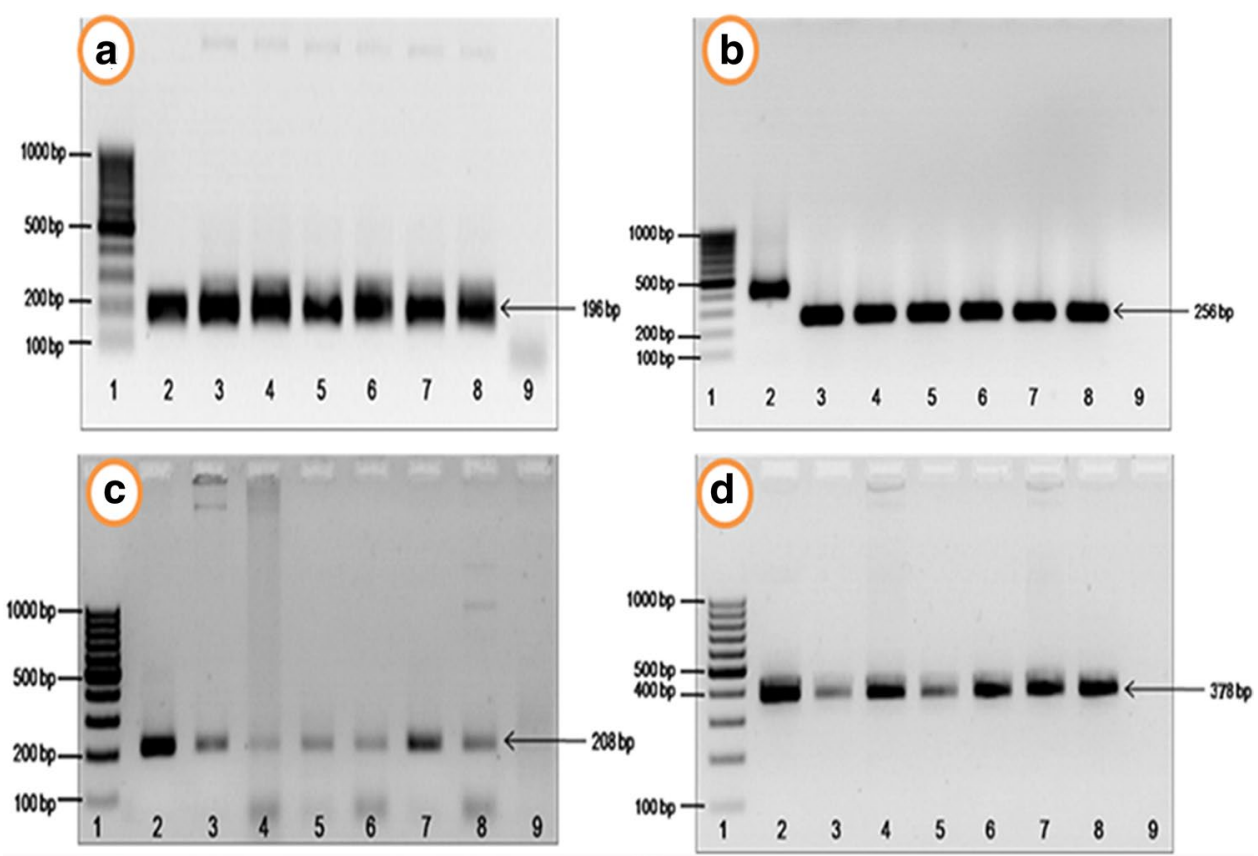

0.56, respectively (Fig. 2). This confirmed the presence of TAs in the fungal extracts.

The MS/MS spectra of fungal hyoscyamine showed the protonated ion at $\mathrm{m} / \mathrm{z} 290.16$ with a minor fragment ion at $m / z, 124.1$ similar with the standard (Fig. 3a, b). The protonated ion of fungal scopolamine showed a very characteristic peak at $m / z 304.15$ and fragmented ions of $m / z$ 156 and 138 similar to standard (Fig. 3c, d) demonstrating that these fungal endophytes can produce TAs.
The mycelial and broth extracts were analysed by HPLC in order to quantify the amounts of hyoscyamine and scopolamine produced by these fungi. These compounds were detected in the broth, but not in mycelial extracts suggesting that they were released into the medium in liquid cultures. The standard scopolamine eluted with the Rt $4.08 \mathrm{~min}$ and hyoscyamine observed with the Rt $6.31 \mathrm{~min}$ (Fig. 4a, b) similar peaks corresponding to standards were observed in all the six fungal extracts (Fig. 4c). The maximum amounts of hyoscyamine and scopolamine obtained in the
Fig. 2 TLC analysis of six fungal extracts with standard hyoscyamine and scopolamine. Lane 1: hyoscyamine, Lane 2: scopolamine, Lane 3-8: fungal extracts of Dm 9.3, Dm 10.2, Dm 13.4, Dm 16.3, Dm 17.3 and Dm 18.2, respectively

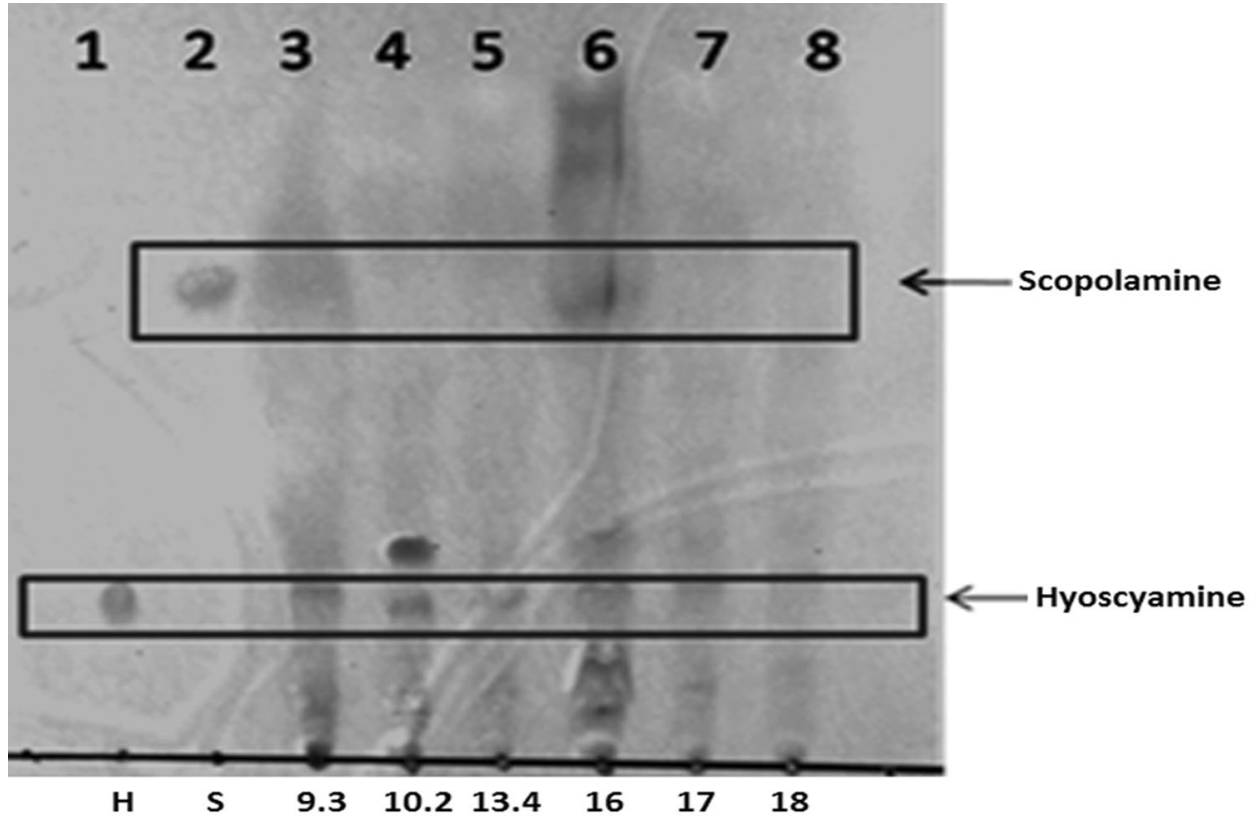



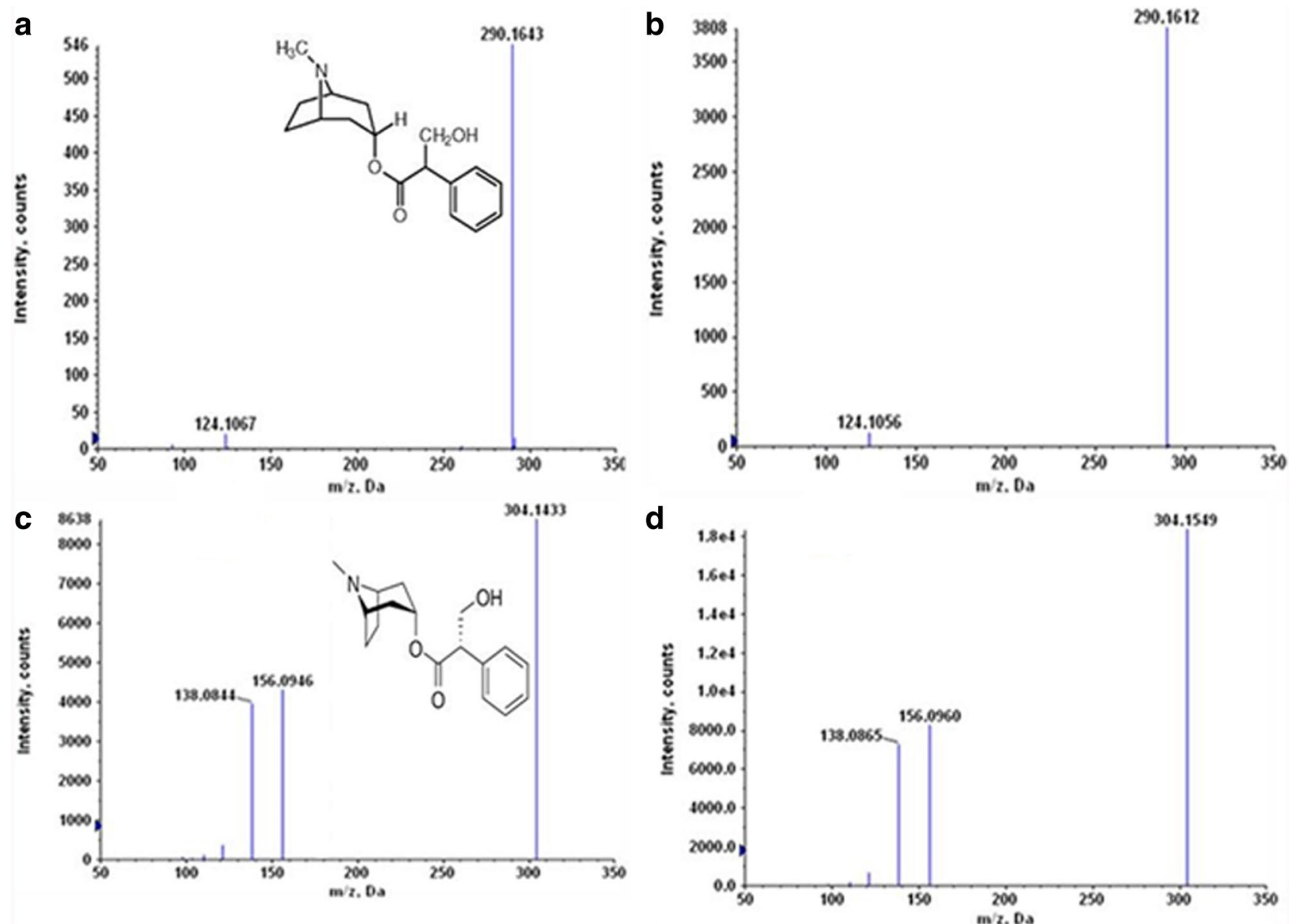

Fig. 3 ESI-MS/MS of standard hyoscyamine (a), fungal hyoscyamine (b), standard scopolamine (c), fungal scopolamine (d) (C. incarnatum)

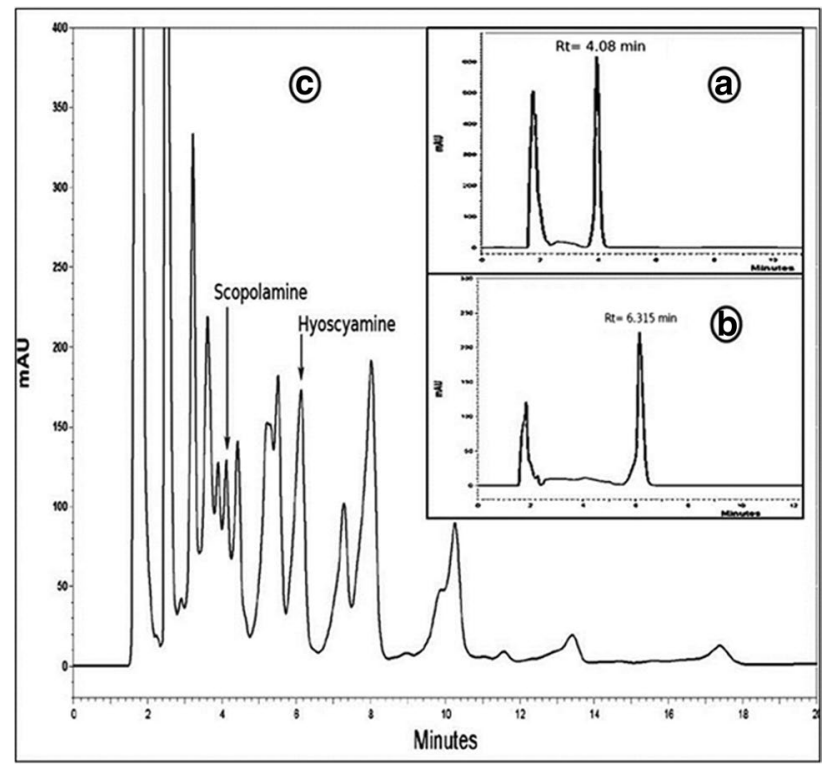

Fig. 4 HPLC separation and quantification of TAs from fungal extract: a standard scopolamine, b standard hyoscyamine, $\mathbf{c}$ fungal hyoscyamine and scopolamine (C. incarnatum)
C. incarnatum were 3.9 and $4.1 \mathrm{mg} / \mathrm{L}$, respectively, followed by other five fungi (Table 1 ).

\section{Discussion}

Plants continue to be the sole source for TAs drugs in view of its commercially unviable complex chemical synthesis [12]. D. metal is one of the major sources of the hyoscyamine and scopolamine [22]. It is believed that the horizontal transfer of some biosynthetic genes of secondary metabolites from the plant to the fungus occurs during their symbiotic association, resulting in the ability of the fungus to produce host plant-specific compounds. The aim of the present investigation was to search for an alternative and viable source of TAs. This is the first report for the isolation, characterization and identification of TAs-producing endophytic fungi from D. metal. The study confirms the presence of PMT, TRI and $H 6 H$ genes in six endophytic fungi out of 18 fungi by gPCR approaches. Earlier searches reported the production of TAs from endophytic actinomycetes of $D$. stramonium not from 
Table 1 Hyoscyamine and scopolamine production by the six fungal isolates by HPLC quantification

\begin{tabular}{lllll}
\hline S. no. & $\begin{array}{l}\text { Endophytic } \\
\text { fungal code }\end{array}$ & Name of the endophytic fungi & Hyoscyamine $(\mathrm{mg} / \mathrm{L})$ & Scopolamine $(\mathrm{mg} / \mathrm{L})$ \\
\hline 1 & Dm 9.3 & C. boninense & $3.4 \pm 0.9^{\mathrm{c}}$ & $1.6 \pm 0.2^{\mathrm{b}}$ \\
2 & Dm 10.2 & Phomopsis $\mathrm{sp}$. & $3.0 \pm 0.3^{\mathrm{d}}$ & $0.5 \pm 0.1^{\mathrm{f}}$ \\
3 & Dm 13.4 & F. solani & $2.6 \pm 0.4^{\mathrm{e}}$ & $1.0 \pm 0.2^{\mathrm{c}}$ \\
4 & Dm 16.3 & C. incarnatum & $3.9 \pm 0.3^{\mathrm{a}}$ & $4.1 \pm 0.8^{\mathrm{a}}$ \\
5 & Dm 17.2 & C. siamense & $3.6 \pm 1.0^{\mathrm{b}}$ & $0.8 \pm 0.5^{\mathrm{d}}$ \\
6 & Dm 18.2 & C. gloeosporioides & $2.2 \pm 0.4^{\mathrm{f}}$ & $0.7 \pm 0.5^{\mathrm{e}}$ \\
\hline
\end{tabular}

Values sharing a common letter within a column are not significant at $p<0.05$; values are mean $\pm \mathrm{SD}$ $(n=3)$ endophytic fungi [14]. However, the molecular marker based screening of endophytic fungi for taxol production was studied by Xiong et al. [28] supports our findings. Moreover, the high homology of PMT, TRI and $H 6 H$ genes between fungal and plant origin suggested that the genetic recombination of the endophytes with its host in evolutionary time could have led to the incorporation of the pathway genes into endophytes from its host [26]. In this study, based on molecular and morphological data, the gene positive fungi were identified as C. boninense (Dm 9.3), Phomopsis sp. (Dm 10.2), F. solani (Dm 13.4), C. incarnatum (Dm 16.3), C. siamense (Dm 17.3) and C. gloeosporioides (Dm 18.2), which were determined first time in $D$. metal plant. MNGB media was a very good base for the production of antimicrobial compounds and also for the production of TAs [14].

In the present work, the crude extracts extracted from 3 weeks fungal broth was examined by chromatography and spectroscopy analysis (TLC, HPLC and MS/MS) to confirm the TAs production. The TLC analysis of the methanol extracts showed the presence of TAs and they displayed the chromatographic properties and $R_{f}$ value similar to standards. The fungal hyoscyamine and scopolamine ions mass fragmentation behaviour from MS/MS exhibited high similarities to standards and this mass ions fragmentation behaviour found to be similar to earlier report [3]. The HPLC analysis confirmed the presence of hyoscyamine and scopolamine with a peak retention time of 4.08 and 6.31, respectively, similar to standards, which indicates these six endophytic fungi are potential for the production of TAs. However, the scopolamine content and scopolamine/hyoscyamine ratio was found to be high in $C$. incarnatum. In contrast, the hyoscyamine levels are higher than the scopolamine in the case of other five fungi, indicating that the Colletotrichum species can be potential candidate for TAs commercial production. In recent years, reports mentioning fungal endophytes capable of producing natural products with therapeutic potential similar to their host plant compounds $[2,8,24]$. Some examples include endophytes producing paclitaxel [23], Podophyllotoxin [4] and camptothecin [11]. To meet the commercial need for scopolamine and hyoscyamine, further work will focus on biotechnological approaches such as strain improvement, genetic manipulation and fermentation engineering.

\section{Conclusion}

In conclusion, 18 endophytic fungi were isolated from $D$. metel and 6 were identified as TAs-producing endophytic fungi by screening the 3 key genes of TAs biosynthetic pathway using gPCR. Moreover, the biosynthetic genes of fungal sequences showed the high homology with plant origin. This is the first report of TAs-producing endophytic fungi from $D$. metel. C. incarnatum showed the highest yields of hyoscyamine and scopolamine. These endophytic fungi could be the potential candidates to be applied in fermentation technology to meet the demands for TAs economically.

Acknowledgements This work was supported by a grant BT/ PR14760/NDB/52/188/2010 to CJB from the Department of Biotechnology (DBT), Government of India, New Delhi, India. VSC and MC thank the Department of Biotechnology and UGC, New Delhi, India for Post-Doctoral fellowship awards. SK thanks DST-SERB New Delhi, India for the young scientist award. We also thank DBT-IISC Partnership Programme, DST-FIST sponsored by GOI New Delhi, India and UGC special Assistance programme for financial support and providing facilities. We also thank emeritus Prof. T. Ramasarma and Prof. R. Manjunath for critical review of the manuscript.

\section{Compliance with Ethical Standards}

Conflict of interest The authors declare that they have no conflict of interest.

\section{References}

1. Afsharypuor S, Mostajeran A, Mokhtary R (1995) Variation of scopolamine and atropine in different parts of Datura metel during development. Planta Med 61:383-384

2. Aly AH, Debbab A, Kjer J, Proksch P (2010) Fungal endophytes from higher plants: a prolific source of phytochemicals and other bioactive natural products. Fungal Divers 41:1-16 
3. Boros B, Farkas A, Jakabova S, Bacskay I, Killar F, Felinger A (2010) LC-MS quantitative determination of atropine and scopolamine in the floral nectar of Datura species. Chromatographia Suppl 71(1):43-49

4. Eyberger AL, Dondapati R, Porter JR (2006) Endophyte fungal isolates from Podophyllum peltatum produce podophyllotoxin. $\mathrm{J}$ Nat Prod 69:1121-1124

5. Firakova S, Sturdikova M, Muckova M (2007) Bioactive secondary metabolites produced by microorganisms associated with plants. Biologia 62:251-257

6. Gontier E, Sangwan BS (1994) Effects of calcium-alginate and calcium-alginate immobilization on growth and tropane alkaloid levels of a stable suspension cell line of Datura anoxia Mill. Plant Cell Rep 13:533-536

7. Griffin WJ, Lin GD (2000) Chemotaxonomy and geographical distribution of tropane alkaloids. Phytochemistry 53:623-637

8. Gunatilaka AAL (2006) Natural products from plant-associated microorganisms: distribution, structural diversity, bioactivity, and implications of their occurrence. J Nat Products 69:509-526

9. Kim WK, Mauthe W, Hausner G, Klassen GR (1990) Isolation of high molecular weight DNA and double-stranded RNAs from fungi. Can J Bot 68:1898-1902

10. Kuriakose GC, Singh S, Rajvanshi PK, Surin WR, Jayabaskaran C (2014) In vitro cytotoxicity and apoptosis induction in human cancer cells by culture extract of an endophytic Fusarium solani strain isolated from Datura metel L. Pharm Anal Acta 5:293

11. Kusari S, Zuhlke S, Spiteller M (2009) An endophytic fungus from Camptotheca acuminata that produces camptothecin and analogues. J Nat Prod 72:2-7

12. Kutchan TM (1996) Heterologous expression of alkaloid biosynthetic genes: a review. Gene 179:73-81

13. Muthumary J (2013) Indian coelomycetes. MJP Publishers, Chennai, pp 84-94

14. Nirmal Christhudas IVS, Kumar PP, Agastian P (2012) Antimicrobial activity and HPLC analysis of tropane alkaloids in Streptomyces spp. isolated from Datura stramonium L. Asian J Pharm Clin Res 5(4):278-282

15. Oksman-Caldentey KM, Hakkinen ST, Rischer H (2007) Metabolic engineering of the alkaloid biosynthesis in plants: functional genomic approaches. In: Verpoorte R, Alfermann AW, Johnson TS (eds) Applications of plant metabolic engineering. Springer, Heidelberg

16. Onions A, Allosopp MS, Eggins D (1981) Smith's introduction to industrial mycology, 7th edn. Arnold, London, p. 398

17. PalazoAn J, Altabella T, CusidoA RM, RiboA M, PinAol MT (1995) Growth and tropane alkaloid production in Agrobacterium transformed roots and derived callus of Datura. Biol Plant 37:161-168

18. Pinkerton F, Strobel G (1976) Serinol as an activator of toxin production in attenuated cultures of Helminthosporium sacchari. PNAS 73:4007-4011

19. Pramod KK, Singh S, Jayabaskaran C (2010) Expression of hyoscyamine $6 \beta$-hydroxylase in the root pericycle cells and accumulation of its product scopolamine in leaf and stem tissues of Datura metel L. Plant Sci 178:202-206

20. Richards TA, Soanes DM, Foster PG, Leonard G, Thornton CR, Talbot NJ (2009) Phylogenomic analysis demonstrates a pattern of rare and ancient horizontal gene transfer between plants and fungi. Plant Cell Online 21:1897-1911

21. Shankar Naik B, Shashikala J, Krishnamurthy YL (2007) Diversity of fungal endophytes in shrubby medicinal plants of Malnad region, Western Ghats, Southern India. Biologia Bratislava 62(3):251-257

22. Sharma V, Sharma N, Singh B, Gupta RC (2009) Cytomorphological studies and HPTLC fingerprinting in different plant parts of three wild morphotypes of Datura metel L. "Thorn Apple" from North India. Int J Green Pharm 3:40-46

23. Stierle A, Strobel G, Stierle D (1993) Taxol and taxane production by Taxomyces andreanae, an endophytic fungus of Pacific yew. Science 260:214-216

24. Strobel G, Daisy B, Castillo U, Harper J (2004) Natural products from endophytic microorganisms. J Nat Prod 67:257-268

25. Sutton BC (1980) The Coelomycetes. Fungi imperfecti with pycnidia, acervuli and stromata. Commonwealth Mycological Institute, Kew, p. 696

26. Tan RX, Zou WX (2001) Endophytes: a rich source of functional metabolites. Nat Prod Rep 18:448-459

27. Weinberger N (2006) Food for thought: honeybee foraging, memory, and acetylcholine. Signal Transduction Knowl Sci Signal $336: 23$

28. Xiong Z, Yang Y, Zhao N, Wang Y (2013) Diversity of endophytic fungi and screening of fungal paclitaxel producer from Anglojap yew,Taxus $x$ media. BMC Microbiol 13:71

29. Zarate R, Jaber-Vazdekis N, Medina B, Ravelo AG (2006) Tailoring tropane alkaloid accumulation in transgenic hairy roots of Atropa baetica by over-expressing the gene encoding hyoscyamine 6b-hydroxylase. Biotechnol Lett 28:1271-1277

30. Zhang L, Ding R, Chai Y, Bonfill M, Moyano E, Oksman-Caldentey KM, Xu T, Pi Y, Wang Z, Zhang H, Kai G, Liao Z, Sun $X$, Tang K (2004) Engineering tropane biosynthetic pathway in Hyoscyamus niger hairy root cultures. Proc Natl Acad Sci USA 101:6786-6791 